\title{
Comparing Meta-Analyses and Pre-Registered Multiple Labs Replication Projects
}

\author{
Amanda Kvarven ${ }^{1, \dagger}$, Eirik Strømland ${ }^{1, \dagger}$, Magnus Johannesson ${ }^{2 *}$
}

1 Department of Economics, University of Bergen, P.O. 7802, 5020 Bergen, Norway

2 Department of Economics, Stockholm School of Economics, Box 6501, SE-113 83 Stockholm, Sweden

${ }^{*}$ To whom correspondence should be addressed. E-mail: Magnus.Johannesson@,hhs.se

${ }^{\dagger}$ These authors contributed equally to this work. 


\begin{abstract}
Many researchers rely on meta-analysis to summarize research evidence. However, recent replication projects in the behavioral sciences suggest that effect sizes of original studies are overestimated, and this overestimation is typically attributed to publication bias and selective reporting of scientific results. As the validity of meta-analyses depends on the primary studies, there is a concern that systematic overestimation of effect sizes may translate into biased metaanalytic effect sizes. We compare the results of meta-analyses to large-scale pre-registered replications in psychology carried out at multiple labs. The multiple labs replications provide relatively precisely estimated effect sizes, which do not suffer from publication bias or selective reporting. Searching the literature, 17 meta-analyses - spanning more than 1,200 effect sizes and more than 370,000 participants - on the same topics as multiple labs replications are identified. We find that the meta-analytic effect sizes are significantly different from the replication effect sizes for 12 out of the 17 meta-replication pairs. These differences are systematic and on average meta-analytic effect sizes are about three times as large as the replication effect sizes.
\end{abstract}




\section{Introduction}

In the last 30 years, there has been an almost exponential growth in the number of meta-analyses across scientific fields ${ }^{1}$. Meta-analyses are viewed as an attractive way to quantitatively summarize a body of research, increase statistical power far beyond that of individual studies and may be a necessary tool to navigate in increasingly large scientific literatures ${ }^{2-4}$. However, it is unclear to what extent meta-analysis provide unbiased estimates of effect sizes. The properties of a meta-analytic effect size depends on the properties of the individual studies included in a meta-analysis; if the individual studies systematically over- or underestimate effect sizes the meta-analysis will too.

There has been a recent surge of replication studies in the behavioral sciences, testing to what extent original studies systematically overestimate effect sizes ${ }^{5-10}$. The pioneering Reproducibility Project: Psychology (RP:P) replicated 100 studies in psychology and found that effect sizes were on average about twice as large in the original studies as in the replication studies. Similar relative effect sizes were reported by the Experimental Economics Replication Project and the Social Sciences Replication Project ${ }^{5,6}$. The substantially higher effect sizes in the original studies compared to the replications is likely to be at least partially caused by publication bias and selective reporting of statistically significant results ${ }^{11-19}$. Some argue that meta-analysis may exacerbate the problems of selective reporting and that greater reliance on meta-analytic thinking in the behavioral sciences will increase the rate of false positives ${ }^{20}$. Others argue that by adopting a broad focus and including both published and unpublished studies, meta-analyses will reduce the influence of publication bias and help improving reproducibility in the behavioral sciences ${ }^{2}$. It is a priori difficult to know which of these positions are correct, and in this study, we provide some evidence on this issue.

Our approach is to use large-scale registered replication studies in Psychology carried out at multiple labs - where publication bias and selective reporting of results is eliminated by 
construction - as a baseline to which the results of meta-analyses on the same topics will be compared. We refer to these studies as replication studies and replication effect sizes below, and contrast these with meta-analysis studies and meta-analytic effect sizes. We furthermore refer to the study being replicated as the original study. We focus only on multiple labs replications as they involve large sample sizes leading to relatively precisely estimated effect sizes. This increases the statistical power of finding a significant difference between replication effect sizes and meta-analytic effect sizes. Note also that the multiple labs replication studies are in themselves meta-analyses as they use meta-analysis to pool effect sizes across labs. But due to the pre-registration they do not suffer from publication bias or selective reporting. Using our methodology, we can both estimate the fraction of studies for which replication effect sizes and meta-analytic effect sizes differ significantly, and we can estimate to what extent these differences are systematic leading to systematically higher or lower effect sizes in meta-analysis studies.

\section{Study Design and Methods}

The inclusion of studies is illustrated in Fig. 1. We start by collecting data on all studies in Psychology where many different laboratories joined forces to replicate a well-known effect according to a pre-defined analysis plan. We identified two data sources in line with this criterion, i) replications published according to the "Registered Replication Report" format in the two journals Perspectives on Psychological Science and Advances in Methods and Practices in Psychological Science ${ }^{21}$ and ii) The "Many Labs" projects in Psychology $\mathrm{y}^{7-9}$. These two data sources have in common that they feature a set of independent laboratories replicating some original study according to a pre-defined analysis plan. We identified 62 such replication effects from these two sources. 
After identifying relevant replication experiments, we searched for meta-analyses on the same research question (see Supplementary Methods, section 1 for details). An initial search identified 39 studies of potential interest who were further assessed for eligibility (see Supplementary Table 1). Out of these 39 meta-analyses, 19 were excluded due to a lack of correspondence in the effects estimated in the meta-analyses and the replication studies, and 2 were excluded due to lack of data. Out of the remaining 18 meta-analyses, two of them studied the same effect. To ensure that our observations are statistically independent we chose to include the largest meta-analysis in the main analysis and include the other in a robustness test. One of the remaining 17 meta-analyses included two replication estimates from two different scenarios from the same original study, and we therefore pooled these two replication effect sizes into one estimate. Another of the remaining 17 meta-analyses had three separate estimates that could be matched to the same replication estimate, and we therefore picked the most precise of these for inclusion in the main analysis and included the other two estimates in robustness checks (see Supplementary Methods, Section 1, for details about the inclusion of studies). In total we therefore include 17 replication-meta pairs in our baseline analysis, and our final data set spans 17 pre-registered replication studies using a multiple labs format $(\mathrm{N}=53,365$ subjects in total) and 17 corresponding meta-analyses on the same research question $(\mathrm{N}=373,367$ subjects in total).

Out of these 17 studies, 13 meta-analyses included the original study replicated in the replication studies and one meta-analysis included the replication study. For the 13 metaanalyses that included the original study our judgment and the judgments of the original metaanalysts coincided by definition; and we will provide a robustness test using this sub-sample below (see Supplementary Methods, Section 1, for a discussion of the 4 meta-analyses that did not include the original study). 
We converted all effect sizes to Cohen's D, and we compare the meta-analytic effect size to the replication effect size for each effect using a z-test (see Supplementary Methods, Section 1, for details). All our statistical tests are two-tailed and follow the recent recommendation to refer to tests with a $p$-value $<0.005$ as "statistically significant" and $p=0.05$ as "suggestive evidence" against the null ${ }^{23}$. In Fig. 2 we show the $95 \%$ and $99.5 \%$ confidence intervals of the meta-analytic effect size and the replication effect size for each study-pair (Panel A), and we show the confidence intervals of the difference in the effect sizes for each study pair (Panel B). The direction of the effect sizes is based on the direction of the effect reported in the original study that was replicated (a positive effect implies an effect in the same direction as the original study and a negative effect implies an effect in the opposite direction).

\section{Results}

As seen in Panel A of Fig. 2, the meta-analyses and replication studies reach the same conclusion about the direction of the effect using the 0.005 statistical significance criterion for $9(53 \%)$ study-pairs; in 7 cases both the meta and the replication studies find a significant effect in the same direction as the original study, and for 2 cases both cannot reject the null hypothesis of no effect. For the remaining $8(47 \%)$ study pairs the meta-analysis finds a significant effect in the original direction whereas the replication cannot reject the null hypothesis. In Panel B, we can see that the difference in estimated effect sizes is significant for $12(70.6 \%)$ of the studies, and there is suggestive evidence for a difference for two additional studies. For all these 14 studies the effect size is higher in the meta-analysis.

The observed rate of significant differences in effects sizes between meta-analyses and replication studies is high. It is possible that this high rate of disagreement is caused by more heterogeneity in effect sizes in meta-analyses. In the replication studies the experimental design is the same for all the contributing labs, whereas there can be design differences in the studies 
included in the meta-analyses depending on the inclusion criteria used by the meta analysts. These design differences may increase heterogeneity and contribute towards the observed rate of disagreement in results. However, higher heterogeneity per se in the meta-analysis studies would not be expected to lead to systematically higher or lower effect sizes. To further estimate to what extent there are systematic differences in average effect sizes between meta-analyses and replication studies we use different meta-analytic models to estimate the pooled effect-size difference across the 17 studies (see Supplementary Methods, Section 2 for details). We estimate these results using an unweighted mean weighting all studies equally, a fixed effects model, and a random effects model. In Panel A of Fig. 2, we first report the pooled replication effect size and the pooled meta-analytic effect size with the three methods. The mean replication effect size across the 17 studies expressed in Cohen's D units varies between 0.105 and 0.142 for the three methods and the mean meta-analytic effect size varies between 0.344 and 0.422 . In Panel B we show the confidence interval for the mean pooled difference in the replication and meta-analytic effect size, which varies between 0.232 and 0.280 and is highly significant for all the three different meta-analytic models we consider. Note that the mean pooled difference in Panel B only coincides with the difference in the mean pooled replication effect size and the mean pooled meta-analytic effect size in Panel A for the unweighted mean, whereas this will not be the case for the fixed effects and random effects models as studies will be weighted differently in the two panels. The estimated mean pooled difference implies a sizeable systematic difference in replication and meta-analytic effect sizes. The relative effect size based on the unweighted means is 2.97 , implying that the mean meta-analytic effect size is about three times as large as the mean replication effect size. The fixed effects and random effects models imply similar large differences.

In Fig. 3 we report several robustness tests and sub-group analyses of the difference in the mean meta-analytic effect size and the mean replication effect size. We estimate results with 
both random effects and fixed effects meta-analysis when we pool differences in effect sizes across studies (see also Supplementary Figure 1 for the unweighted results). We do three robustness tests on the inclusion criteria: excluding unpublished meta-analyses $(\mathrm{N}=3)$ so that our analysis sample is $\mathrm{N}=14$; excluding meta-analyses that included the replication study $(\mathrm{N}=1)$ so that our analysis sample is $\mathrm{N}=16$; and excluding the meta-analyses $(\mathrm{N}=4)$ that did not include the original study that was replicated so that our analysis sample is $\mathrm{N}=13$. In an additional robustness test we also use the alternative meta-analysis for the replication study where we identified two meta-analyses. In two final robustness checks we use the two alternative metaanalysis estimates reported in the same meta-analysis paper corresponding to the Graham, Haidt $\&$ Nosek (2009) $)^{32}$ original study. The results are similar to the main results in these robustness tests.

We also carry out several sub-group analyses. We estimate results separately for cases where both the meta-analysis and replication reported their effect size so that we could directly estimate the difference in Cohen's D units $(\mathrm{N}=7)$ and cases where we had to manually convert either the replication effect, meta-analysis effect or both $(\mathrm{N}=10)$. This is to ensure that our main results are not driven by our conversions of the effect sizes. The results are similar in these two sub-groups. We also report results separately for replications from one of the Many Labs projects $(\mathrm{N}=10)$ and replications from Registered Report Replications studies $(\mathrm{N}=7)$ as the selection of studies to replicate can differ between these. The results are similar in these two sub-groups as well, although with a slightly larger point estimate of the difference for the Registered Replication Report studies.

Finally, we separate results into sub-groups depending on if the effect was significant in the replication study or not; we define these groups both based on the $\mathrm{p}<0.005$ significance threshold and the $\mathrm{p}<0.05$ threshold. This is to test if the difference between the meta analytic and the replication effect size is driven by studies where the null hypothesis cannot be rejected 
in the replication. If the null hypothesis is true, selective publication may not necessarily result in biased meta-analytic effect sizes if "significant" results with positive and negative signs cancel out. However, Nelson, Simmons, and Simonsohn ${ }^{20}$ suggest that meta-analyses are prone to produce false positives, and that aggregation in meta-analyses in general does not lead errors to cancel out. Supporting this mechanism, we find a significant and large difference measure between the meta-analytic and replication effect sizes for the replication studies that cannot reject the null hypothesis. Although the point estimates are smaller, the difference measure is significant also for replication studies rejecting the null hypotheses using the $\mathrm{p}<0.05$ threshold and suggestive when using the $\mathrm{p}<0.005$ threshold, suggesting that effect size inflation of both true hypotheses and false positives may contribute to our results. We furthermore tested if the difference measure is significantly smaller for replication studies rejecting the null hypothesis than for replication studies failing to reject the null hypothesis, but found no evidence for this (Supplementary Table 2).

\section{Discussion}

To summarize our findings, we find that there is a significant difference between the metaanalytic effect size and the replication effect size for 12 of the 17 studies $(70.6 \%)$, and suggestive evidence for a difference in two additional studies. These differences are systematic - the meta-analytic effect size is larger than the replication effect for all these studies- and on average for all the 17 studies the estimated effect sizes are about 3 times as large in the metaanalyses. Interestingly, the relative difference in estimated effect sizes is of at least the same magnitude as that observed between replications and original studies in the RP:P and other similar systematic replication projects ${ }^{5,6,10}$. Publication bias and selective reporting in original studies has been suggested as possible reasons for the low reproducibility in RP:P and other 
replication projects, and our results suggest that these biases are not eliminated by the use of meta-analysis.

To test further whether meta-analyses reduce the influence of publication bias or selective reporting, we compare the average unweighted effect size of the original studies to the meta-analyses. We were able to obtain effect sizes of the original studies converted to Cohen's D for all original studies except one where the standard deviation was unavailable. ${ }^{41}$ We were additionally able to compute a valid standard error for 14 out of 17 original studies. The average unweighted effect size of these 14 original studies is 0.561 , which is about $42 \%$ higher than the average unweighted effect size of 0.395 of the same 14 studies in the meta-analyses. These point estimates are consistent with meta-analyses reducing the effect sizes estimated in original studies somewhat, and in formal meta-analytic models the estimated difference between the original effect and the summary effect in the meta-analysis varies between 0.089 and 0.166 . These estimated differences are not statistically significant but suggestive of a difference in all three cases using our criterion for statistical significance. (see Supplementary Table 3 for details). Further work on larger samples are needed to more conclusively test if meta-analytic effect sizes differ from original effect sizes.

In a previous related study in medicine, 12 large randomized, controlled trials published in four leading medical journals were compared to 19 meta-analyses published previously on the same topics. ${ }^{24}$ They compared several clinical outcomes between the studies and found a significant difference between the meta-analyses and the large clinical trials for $12 \%$ of the comparisons. They did not provide any results for the pooled overall difference between metaanalyses and large clinical trials, but from graphically inspecting the results there does not appear to be a sizeable systematic difference. Those previous results for medicine are thus different from our findings. This could reflect a genuine difference between psychology and medicine, but it could also reflect that even large clinical trials in medicine are subject to 
selective reporting or publication bias or that large clinical trials with null results are published in less prestigious journals.

Although we believe the most plausible interpretation of our results is that metaanalyses overestimate effect sizes on average in our sample of studies, there are other possible explanations. In testing a specific scientific hypothesis in an experiment there can be heterogeneity in the true effect size due to several sources. The true effect size can vary between different populations (sample heterogeneity) and the true effect size can vary between different experimental designs to test the hypothesis (design heterogeneity). If the exact statistical test used or the inclusion/exclusion criteria of observations included in the analysis differ, this will yield a third source of heterogeneity in estimated effect sizes (test heterogeneity). In the multiple lab replications included in our study the design and statistical tests used is held constant across the labs, whereas the samples vary across labs. The effect sizes across labs will therefore vary due to sample heterogeneity, but not due to design or test heterogeneity. In the meta-analyses the effect sizes can vary across the included studies due to sample, design- and test heterogeneity. Sample, design or test heterogeneity could potentially explain our results.

For sample heterogeneity to explain our results, the replications need to have been conducted in samples with on average lower true effect sizes than the samples included in the studies in the meta-analyses. We find this explanation for our results implausible. The Many Labs studies estimate the sample heterogeneity and only find small or moderate heterogeneity in effect $\operatorname{sizes}^{7-9}$. In the recent Many Labs 2 study the average heterogeneity measured as the standard deviation in the true effect size across labs (Tau) was $0.04^{8}$. This can be compared to the measured difference in meta-analytic and replication effect sizes in our study of $0.232-0.28$ for the three methods.

For design or test heterogeneity to explain our results it must be the case that replication studies select experimental designs or tests producing lower true effect sizes than the average 
design and test included to test the same hypotheses in meta-analyses. For this to explain our results the design and test heterogeneity in meta-analyses would have to be substantial and the "replicator selection" of weak designs needs to be strong. This potential explanation of our results would imply a high correlation between design and test heterogeneity in the metaanalysis and the observed difference in the meta-analytic and replication effect sizes; as a larger design and test heterogeneity increases the scope for "replicator selection". To further shed some light on this possibility we were able to obtain information about the standard deviation in true effect sizes across studies (Tau) for ten of the meta-analyses in our sample; Tau was reported directly for two of these meta-analyses and sufficient information was provided in the other eight meta-analyses so that we could estimate Tau. The mean Tau was 0.30 in these ten meta-analyses with a range from 0.00 to 0.735 . This is likely to be an upper bound on the design and test heterogeneity as the estimated Tau also includes sample heterogeneity. While this is consistent with a sizeable average design and test heterogeneity in the meta-analyses, it also needs to be coupled with strong "replicator selection" to explain our results. To test for this, we estimated the correlation between the Tau of these ten meta-analyses and the difference in the meta-analytic and replication effect sizes. The Spearman correlation was $-0.1879(p=0.6032)$ and the Pearson correlation was $-0.3920(\mathrm{p}=0.2626)$, showing no sign of the observed differences in effect sizes to be related to the scope for "replicator selection". In fact, the estimated correlation is in the opposite direction than the direction predicted by the "replicator selection" mechanism. This tentative finding departs from a recent meta-research paper that attributes reproducibility failures in Psychology to heterogeneity in the underlying effect sizes. ${ }^{25}$ Further work with larger samples is needed on this to more rigorously test for "replicator selection". It should also be noted that the pooled replication rate across Many Labs 1-3 is $53 \%$, which is in line with the replication rate observed in three large scale systematic replication project that should not be prone to "replicator selection" (the Reproducibility 
Project: Psychology ${ }^{10}$, the Experimental Economics Replication Project ${ }^{5}$ and the Social Sciences Replication project ${ }^{6}$ ). This suggests no substantial "replicator selection" in the Many Labs studies that form the majority of our sample.

Another caveat about our results concerns the representativity of our sample. The inclusion of studies was limited by the number of pre-registered multiple labs replications carried out so far, and for which of these studies we could find a matching meta-analysis. Our sample of 17 studies should thus not be viewed as being representative of meta-analysis in psychology or in other fields. In particular, the relative effect between the original studies and replication studies for the sample of studies included in our analysis is somewhat larger than the one observed in previous replication projects ${ }^{5,6,10}$ - indicating that our sample could be a select sample of psychological studies where selective reporting is particularly prominent. In the future the number of studies using our methodology can be extended as more pre-registered multiple labs replications become available and as the number of meta-analyses continue to increase. We also encourage others to test out our methodology for evaluating meta-analyses on an independent sample of studies.

We conclude that meta-analyses produce substantially larger effect sizes than replication studies in our sample. This difference is largest for replication studies that fail to reject the null hypothesis, which is in line with recent arguments about a high false positive rate of meta-analyses in the behavioral sciences ${ }^{20}$. Our findings suggest that meta-analyses is ineffective in fully adjusting inflated effect sizes for publication bias and selective reporting. A potentially effective policy for reducing publication bias and selective reporting is preregistering analysis plans prior to data collection. There is currently a strong trend towards increased pre-registration in psychology 22 . This has the potential to increase both the credibility of original studies, but also of meta-analyses, making meta-analysis a more valuable tool for 
aggregating research results. Future meta-analyses may thus produce effect sizes that are closer to the effect sizes in replication studies. 


\section{References}

1. Gurevitch, J., Koricheva, J., Nakagawa, S., \& Stewart, G. (2018). Meta-analysis and the science of research synthesis. Nature, 555(7695), 175.

2. Cumming, G. (2014). The new statistics: Why and how. Psychological Science, 25(1), 7-29.

3. Siddaway, A. P., Wood, A. M., \& Hedges, L. V. (2018). How to Do a Systematic Review: A Best Practice Guide for Conducting and Reporting Narrative Reviews, MetaAnalyses, and Meta-Syntheses. Annual Review of Psychology, (0).

4. Stanley, T. D. (2001). Wheat from chaff: Meta-analysis as quantitative literature review. Journal of Economic Perspectives, 15(3), 131-150.

5. Camerer, C. F., Dreber, A., Forsell, E., Ho, T. H., Huber, J., Johannesson, M., ... \& Heikensten, E. (2016). Evaluating replicability of laboratory experiments in economics. Science, 351(6280), 1433-1436.

6. Camerer, CF, et al. Evaluating replicability of social science experiments in Nature and Science between 2010 and 2015. Nature Human Behaviour 2, 637-644 (2018).

7. Klein, R. A. et al. Investigating variation in replicability: a "many labs" replication project. Social Psychology 45, 142-152 (2014).

8. Klein, R. A., Vianello, M., Hasselman, F., Adams, B. G., Adams Jr, R. B., Alper, S., ... \& Batra, R. (2018). Many Labs 2: Investigating variation in replicability across samples and settings. Advances in Methods and Practices in Psychological Science, 1(4), 443490.

9. Ebersole, C. R., Atherton, O. E., Belanger, A. L., Skulborstad, H. M., Allen, J. M., Banks, J. B., ... \& Brown, E. R. (2016). Many Labs 3: Evaluating participant pool quality across the academic semester via replication. Journal of Experimental Social Psychology, 67, 68-82.

10. Open Science Collaboration. (2015). Estimating the reproducibility of psychological science. Science, 349(6251), aac4716.

11. Duval, S., \& Tweedie, R. (2000). A nonparametric "trim and fill" method of accounting for publication bias in meta-analysis. Journal of the American Statistical Association, 95(449), 89-98.

12. Ioannidis, J. P. (2005). Why most published research findings are false. PLoS Medicine, 2(8), e124.

13. Ioannidis, J. P. (2008). Why most discovered true associations are inflated. Epidemiology, 640-648. 
14. Simmons, J. P., Nelson, L. D., \& Simonsohn, U. (2011). False-positive psychology: Undisclosed flexibility in data collection and analysis allows presenting anything as significant. Psychological Science, 22(11), 1359-1366.

15. Gelman, A., \& Loken, E. (2014). The statistical crisis in science. American Scientist, 102(6), 460.

16. Gelman, A., \& Carlin, J. (2014). Beyond power calculations: Assessing type S (sign) and type M (magnitude) errors. Perspectives on Psychological Science, 9(6), 641-651.

17. Brodeur, A., Lé, M., Sangnier, M., \& Zylberberg, Y. (2016). Star wars: The empirics strike back. American Economic Journal: Applied Economics, 8(1), 1-32.

18. Andrews, I., \& Kasy, M. (2019). Identification of and correction for publication bias. American Economic Review (Forthcoming)

19. Maniadis, Z., Tufano, F., \& List, J. A. (2014). One swallow doesn't make a summer: New evidence on anchoring effects. American Economic Review, 104(1), 277-90.

20. Nelson, L. D., Simmons, J., \& Simonsohn, U. (2018). Psychology's renaissance. Annual Review of Psychology, 69.

21. Simons, D. J., Holcombe, A. O., \& Spellman, B. A. (2014). An introduction to registered replication reports at perspectives on psychological science. Perspectives on Psychological Science, 9(5), 552-555.

22. Nosek, B. A., Ebersole, C. R., DeHaven, A. C., \& Mellor, D. T. (2018). The preregistration revolution. Proceedings of the National Academy of Sciences, 201708274.

23. Benjamin, D. J., Berger, J. O., Johannesson, M., Nosek, B. A., Wagenmakers, E. J., Berk, R., ... \& Cesarini, D. (2018). Redefine statistical significance. Nature Human Behaviour, 2(1), 6 .

24. LeLorier, J., Gregoire, G., Benhaddad, A., Lapierre, J., Derderian, F. (1997). Discrepancies between meta-analyses and subsequent large randomized, controlled trials. New England Journal of Medicine, 337(8), 536-542.

25. Stanley, T. D., Carter, E. C., \& Doucouliagos, H. (2018). What meta-analyses reveal about the replicability of psychological research. Psychological Bulletin, 144(12), 1325.

26. Oppenheimer, D. M., Meyvis, T., \& Davidenko, N. (2009). Instructional manipulation checks: Detecting satisficing to increase statistical power. Journal of Experimental Social Psychology, 45(4), 867-872.

27. Tversky, A., \& Kahneman, D. (1981). The framing of decisions and the psychology of choice. Science, 211(4481), 453-458. 
28. Husnu, S., \& Crisp, R. J. (2010). Elaboration enhances the imagined contact effect. Journal of Experimental Social Psychology, 46(6), 943-950.

29. Schwarz, N., Strack, F., \& Mai, H. P. (1991). Assimilation and contrast effects in partwhole question sequences: A conversational logic analysis. Public Opinion Quarterly, $55(1), 3-23$.

30. Hauser, M., Cushman, F., Young, L., Kang-Xing Jin, R., \& Mikhail, J. (2007). A dissociation between moral judgments and justifications. Mind \& Language, 22(1), 121.

31. Critcher, C. R., \& Gilovich, T. (2008). Incidental environmental anchors. Journal of Behavioral Decision Making, 21(3), 241-251.

32. Graham, J., Haidt, J., \& Nosek, B. A. (2009). Liberals and conservatives rely on different sets of moral foundations. Journal of Personality and Social Psychology, 96(5), 1029.

33. Galinsky, A. D., Magee, J. C., Inesi, M. E., \& Gruenfeld, D. H. (2006). Power and perspectives not taken. Psychological Science, 17(12), 1068-1074.

34. Jostmann, N. B., Lakens, D., \& Schubert, T. W. (2009). Weight as an embodiment of importance. Psychological Science, 20(9), 1169-1174.

35. Monin, B., \& Miller, D. T. (2001). Moral credentials and the expression of prejudice. Journal of Personality and Social Psychology, 81(1), 33.

36. Finkel, E. J., Rusbult, C. E., Kumashiro, M., \& Hannon, P. A. (2002). Dealing with betrayal in close relationships: Does commitment promote forgiveness?. Journal of Personality and Social Psychology, 82(6), 956.

37. Schooler, J. W., \& Engstler-Schooler, T. Y. (1990). Verbal overshadowing of visual memories: Some things are better left unsaid. Cognitive Psychology, 22(1), 36-71.

38. Sripada, C., Kessler, D., \& Jonides, J. (2014). Methylphenidate blocks effort-induced depletion of regulatory control in healthy volunteers. Psychological Science, 25(6), 1227-1234.

39. Rand, D. G., Greene, J. D., \& Nowak, M. A. (2012). Spontaneous giving and calculated greed. Nature, 489(7416), 427.

40. Strack, F., Martin, L. L., \& Stepper, S. (1988). Inhibiting and facilitating conditions of the human smile: a nonobtrusive test of the facial feedback hypothesis. Journal of Personality and Social Psychology, 54(5), 768. 
41. Srull, T. K., \& Wyer, R. S. (1979). The role of category accessibility in the interpretation of information about persons: Some determinants and implications. Journal of Personality and Social Psychology, 37(10), 1660.

42. Mazar, N., Amir, O., \& Ariely, D. (2008). The dishonesty of honest people: A theory of self-concept maintenance. Journal of Marketing Research, 45(6), 633-644.

\section{Acknowledgements}

For financial support we thank: Jan Wallander and Tom Hedelius Foundation (P2015-0001:1), and Swedish Foundation for Humanities and Social Sciences (NHS14-1719:1). 


\section{FIGURES}

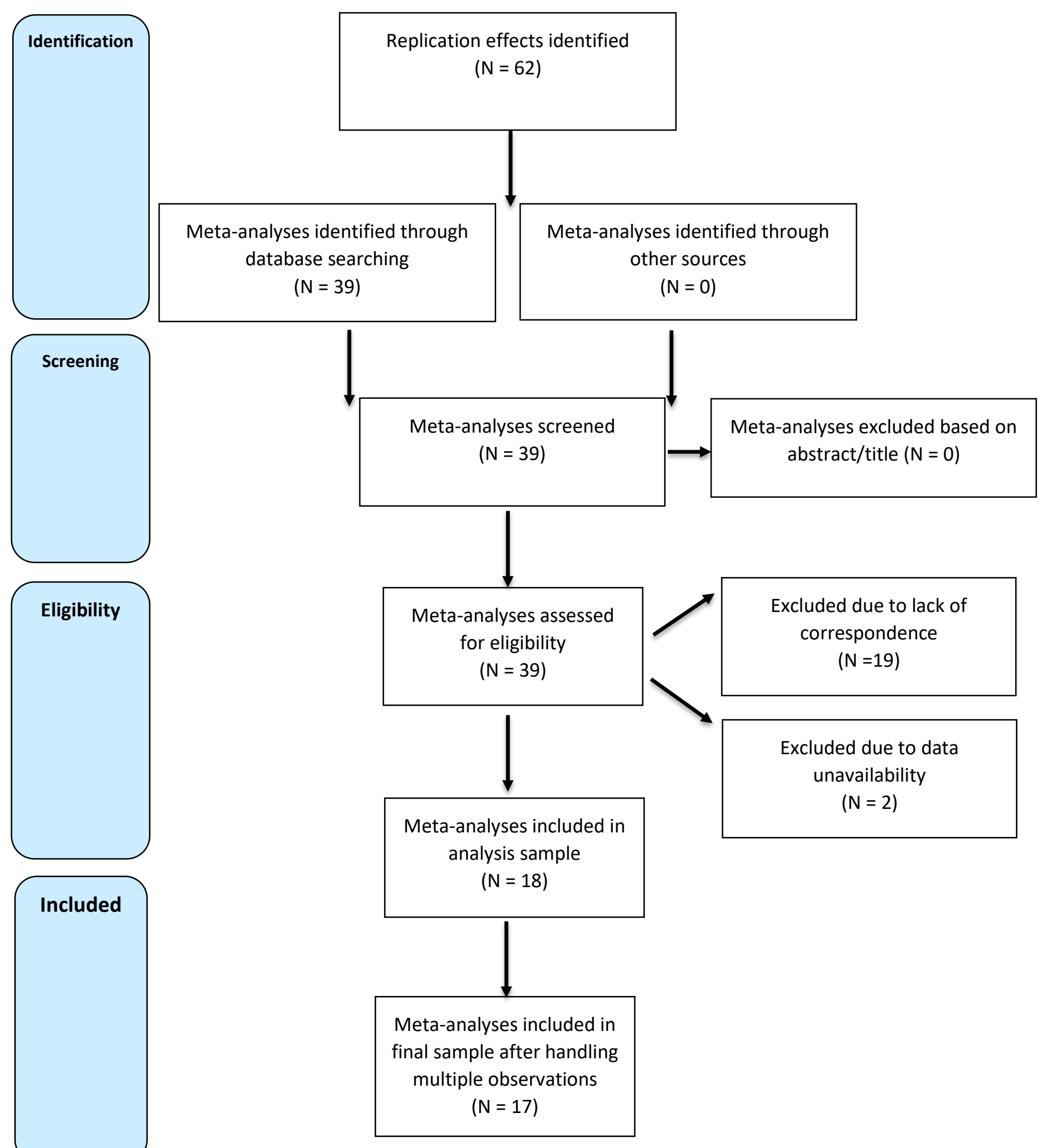


Fig. 1. PRISMA flow-diagram over the number of meta-analyses considered for inclusion. The Figure illustrates our process of data collection leading up to our analysis sample of 17 meta-replication pairs. $\mathrm{N}$ is the number of observations. Note that the flow diagram indexes $\mathrm{N}$ as the number of multiple labs replication studies in the first box and as the number of metaanalyses in the subsequent boxes; not the number of studies included in the meta-analysis as is the conventional use of this diagram in meta-analyses studies. 
A: Meta-Analysis ( $\square$ ) and Replication ( $\square$ ) estimates

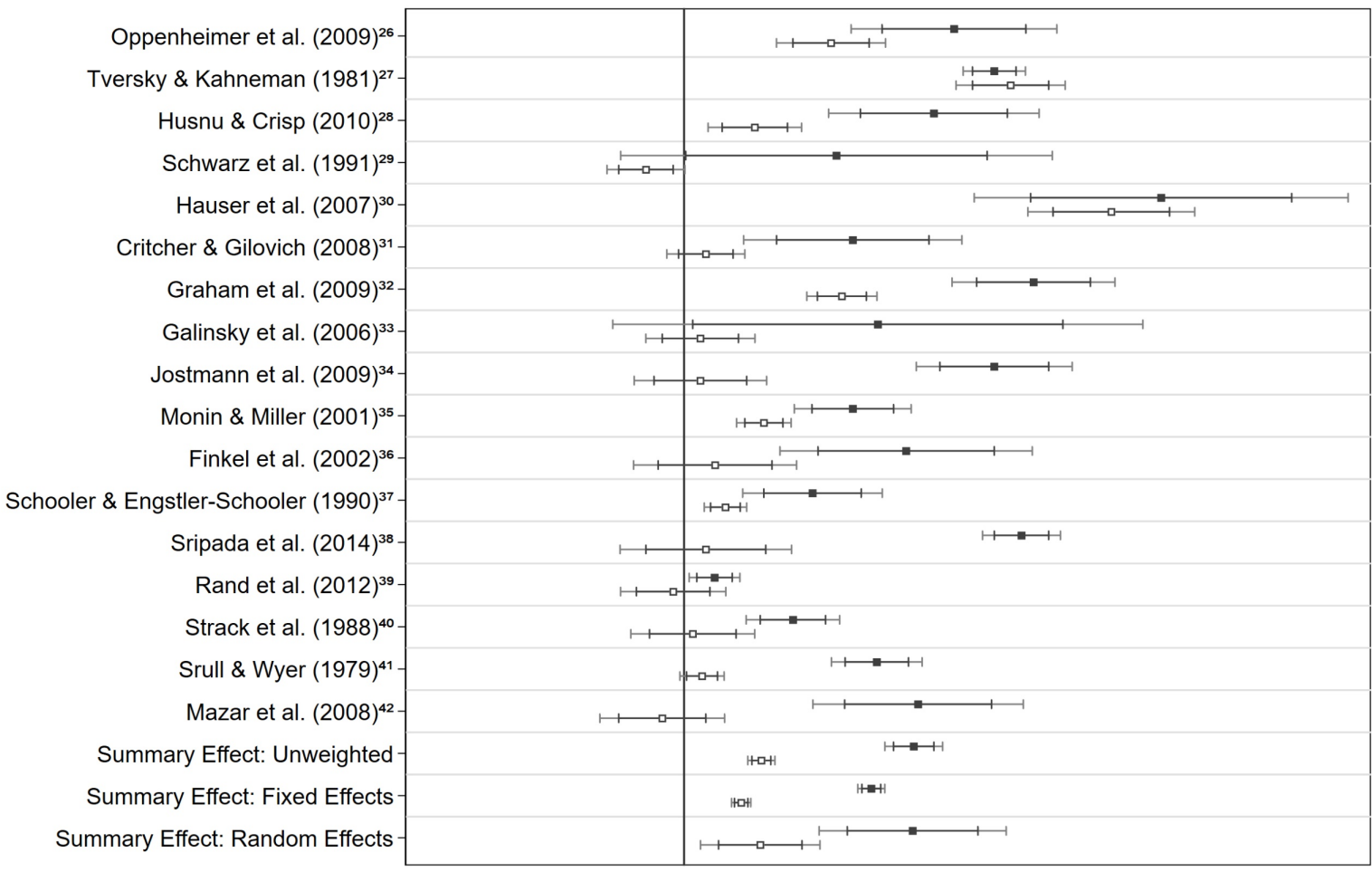

B: Difference (Meta-analysis - Replication)

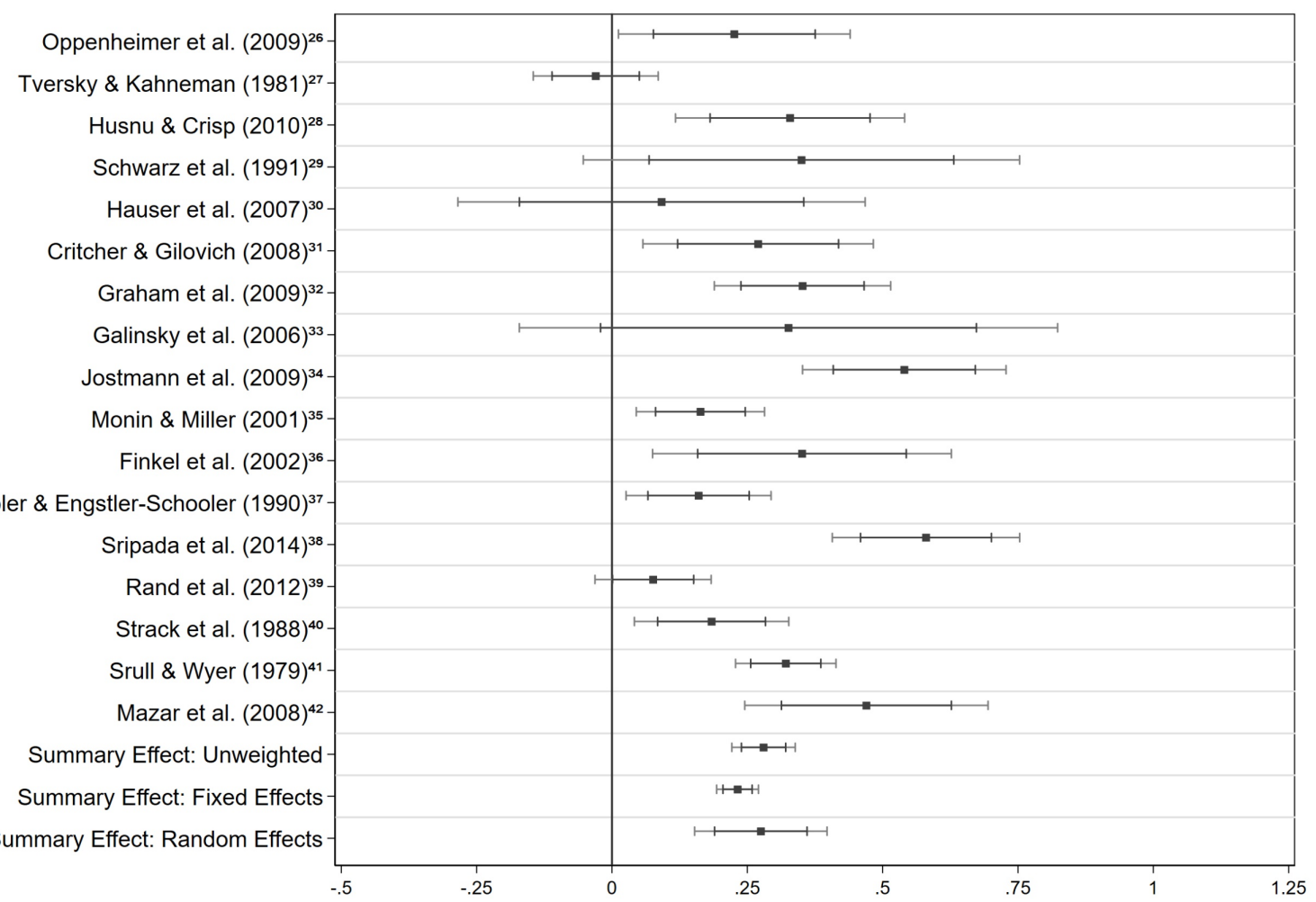




\section{Fig. 2. Results of meta-analyses and replication studies.}

(A) Plotted are $95 \%$ and $99.5 \%$ CIs of meta-analytic effect sizes and replication studies effect sizes for each study-pair estimating the same effects. The final row plots the $95 \%$ and $99.5 \%$ CIs of the mean meta-analytic effect size and the mean replication effect size for all the 17 studied effects for three different statistical models - the Random effects model, the Fixed effects model and a model assigning equal weight to each pair (see Supplementary Methods, Section 2, for a further description of the models used). The references listed in the Figure for the 17 studied effects, are the references to the 16 original studies replicated in the replication studies.

(B) Plotted are $95 \%$ and $99.5 \%$ CIs of the difference in meta-analytic and replication studies effect sizes for each study pair estimating the same effects. The final row plots the $95 \%$ and $99.5 \%$ CIs of the difference in the mean meta-analytic effect size and the mean replication effect size for all the studied effects for three different statistical models - the Random effects model, the Fixed effects model and a model assigning equal weight to each pair (see Supplementary Methods, Section 2, for a further description of the models used). 

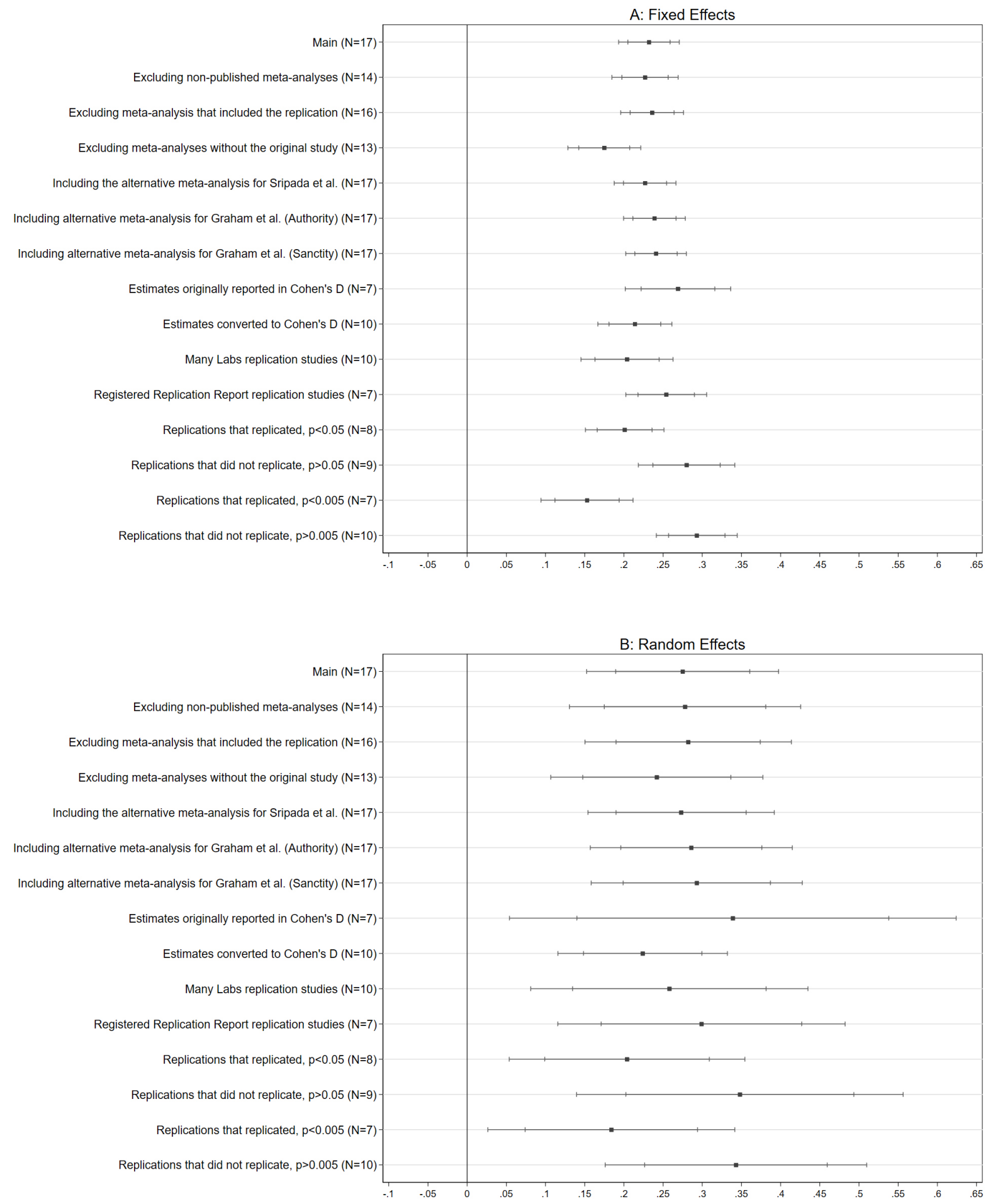

Fig. 3. Robustness test and sub-group analyses of the difference in the mean meta-analytic effect size and the mean replication effect size for all the studied effects. For each robustness test and sub-group analysis we plot the $95 \%$ and $99.5 \%$ confidence interval of the difference in 
the mean meta-analytic effect size and the mean replication effect size for all the studied effects.

"Main" is our main estimate using the entire analysis sample. 
Supplementary Information for

\section{Comparing Meta-Analyses and Pre-Registered Multiple Labs Replication}

\section{Projects}

Amanda Kvarven ${ }^{1}$, Eirik Stromland ${ }^{1}$, Magnus Johannesson ${ }^{2}$

1 Department of Economics, University of Bergen, P.O. 7802, 5020 Bergen, Norway

2 Department of Economics, Stockholm School of Economics, Box 6501, SE-113 83

Stockholm, Sweden

The Supplementary Information contain:

Supplementary Methods

Supplementary References

Supplementary Tables 1-3

Supplementary Figures 1 


\section{Supplementary Methods}

\section{Data collection and conversion of effect sizes}

Our procedures for study identification proceeded as follows. First, we identified all registered replications in Psychology of a multi-lab format. This was done by looking through issues of the journals Perspectives on Psychological Science and Advances in Methods and Practices in Psychological Science that since 2014 have published studies of this format ${ }^{1-11}$. Second, we identified all "Many Labs" projects so far completed ${ }^{12-14}$. In total, this yielded 62 effect sizes for which we would look for a corresponding meta-analysis.

For each of the replication measures two independent researchers searched through Google Scholar for previous - published or unpublished - meta-analyses conducted on the same hypothesis as that investigated in the multi-lab replication. We did two searches, a general search and a more restrictive search. In the general search we searched for key terms in the replication paper (for instance "ego depletion") in combination with "meta analysis". In addition, we did a restricted search where we searched for "meta analysis" and "meta-analysis" in the database of papers in google scholar citing the original study that was subject to replication in the multi-lab study.

Using this procedure, we identified 39 meta-analyses that on an initial screening were deemed relevant to assess for eligibility (see Table S1, for details) ${ }^{15-51}$. Each of the two researchers then assessed eligibility of each of the meta-analyses by reading the paper alongside the papers including the replication estimate and the original estimate ${ }^{52-78}$. For cases that were unclear, agreement was reached through consensus and the third researcher was consulted. 19 meta-analyses were excluded due to a lack of correspondence in the effects estimated in the meta-analyses and the replication studies and 2 were excluded due to lack of data (reducing the sample to 18 meta-analyses). The missing data were due to missing information about the standard errors. For meta-analyses where the standard error was not available from the 
published paper, we had to e-mail the corresponding author of the meta-analysis for the standard error. This was the case for four meta-analyses. In one of these, the corresponding author had died ten years ago, and we failed to find the other authors and this meta-analysis was therefore excluded. ${ }^{47}$ In a second case, the author quickly provided the raw data used in the meta-analysis and this meta-analysis could therefore be included. ${ }^{17}$ In the third case, the author of the metaanalysis replied to our request, but the data were missing as they were collected more than 20 years ago. ${ }^{48}$ Therefore, this study was excluded from our analysis sample due to data unavailability.

For the remaining 18 meta-analyses two of the meta-analyses were for the same replication study; the ego depletion replication (Hagger et al., 2016) ${ }^{4}$. There was one metaanalysis about ego depletion by Hagger et al. $(2010)^{27}$ and one by Carter et al. $(2015)^{28}$. If we included both of these meta-analyses they would not be independent observations and we therefore only included one of them reducing our sample to 17 meta-analyses paired with 17 replication studies. In the main analysis we included the meta-analysis with the largest sample size which was Hagger et al. $(2010)^{27}$, but we also did a robustness test including the Carter et al. $(2015)^{28}$ meta-analysis instead (in Fig. 3).

For the replication of Hauser et al. $(2007)^{57}$ there were two separate replication estimates in Klein et al. $(2018)^{13}$. As the meta-analysis corresponding to these two replication estimates ${ }^{18}$ included both the scenarios subjected to replication and the two replication estimates used different participants, we therefore chose to pool the two replication estimates. We did this by downloading the raw data from Klein et al. $(2018)^{13}$ from the Open Science Framework and ran a random-effects meta-analysis using each estimate and standard error at the laboratory level as our unit of observation, resulting in a single random-effects meta-analytic estimate for this replication. 
For the meta-analysis by Kivikangas et al. (2019) $)^{39}$ corresponding to Graham, Haidt \& Nosek (2009) $)^{72}$, there were three separate estimates of the three "binding foundations" in the meta-analysis, whereas the replication presents a single pooled measure. To ensure that the observations included in our overall measure were statistically independent, we followed our criterion of picking the most precise estimate for inclusion in the main results, and therefore included the "Loyalty" estimate from Kivikangas et al. (2019) ${ }^{39}$. For robustness, in Fig. 3 we present the results using the two other possible choices of meta-analytic estimate instead.

For the replication of Finkel et al. $(2002)^{55}$ by Cheung et al. $(2016)^{5}$ there were two main replication outcomes, corresponding to "Exit" and "Neglect", both of which were measured in the original study. However, both of the replication estimates were identical, and the confidence intervals were very similar as well, so there would essentially be no practical difference depending on which of these estimates were included in the analysis sample. For simplicity we followed our criteria used when picking between multiple meta-analyses of picking the most precise estimate, and therefore included the estimate corresponding to "Exit".

For the 17 meta-analyses included in the final sample, 13 of them included the original study which was replicated in the corresponding replication study. This is an indication that for these 13 studies the meta-analysts and we made the same judgment about the meta-analyses and replication studies estimating the same effects. For the remaining 3 meta-analysis we made the judgment that also these study the same effects as in the corresponding replication studies. We comment on these three cases below:

- Srull \& Wyer (1979). ${ }^{66}$ For the original study of Srull \& Wyer (1979) the meta-analysts explicitly state that they intended to include this study but suspected a statistical error and therefore chose not to include it (so they clearly view the design of the original study to belong in the meta-analysis). 
- Sripada et al. (2014). ${ }^{65}$ The meta-analysis by Hagger et al. $(2010)^{27}$ was published prior to the original study by Sripada et al. (2014), which was replicated in 2015. Moreover, the eletter task included in Sripada et al. (2014) is an electronic modification of a corresponding design used in Baumeister et al. (1998) ${ }^{85}$, which is included in the Hagger et al. metaanalysis. For the subsequent meta-analysis of Carter et al. $(2015)^{28}$ which is included in the robustness test instead of the meta-analysis of Hagger et al. (2010), we do not find an obvious explanation for not including Sripada et al. (2014), but Carter et al. is a well published study and argues that it constitutes an improvement over Hagger et al. (2010).

- Oppenheimer et al. (2009). ${ }^{52}$ The meta-analysis by Roth et al. (2014) ${ }^{23}$ does not include or cite the original study by Oppenheimer et al. (2009), but it cites and includes Thaler $(1985)^{84}$, and Oppenheimer et al. (2009) adapt the sunk cost question directly from Thaler (1985) and use the same wording of the question.

- Graham, Haidt \& Nosek (2009) $)^{72}$ The meta-analysis by Kivikangas et al. (2019) ${ }^{39}$ does not include the original study, but cites the original study as seminal for the literature reviewed, and the authors in fact use the original study as the starting point for defining the search period used to search for relevant studies. The reason for not including the original study is not stated in the meta-analysis.

After deciding on an analysis sample, we obtained the relevant data from the replication study either from the information in the published paper or from the data sets that were publicly available on the Open Science Framework. For the meta-analyses, as far as possible we obtained the data on the summary effect and the standard error of the summary effect from the information available in the published paper. In all but two of the included meta-analyses it was possible to extract the relevant information directly from the paper. In the two other cases we 
had to e-mail the corresponding author of the meta-analysis. Figure 1 presents a visual outline of our data collection procedure.

To facilitate clear interpretation of the results we needed to ensure that the results are measured using the same effect size metric. In most of the cases - for both the replication studies and the meta-analyses - the effect size reported is a standardized Cohen's D measure. However, in a minority of the cases a correlation coefficient (Pearson's $r$ or Fisher's Z) is reported, and some studies report an unconverted "natural unit" of the effect as their main measure - e.g. the percentage point difference between treatments. To put all our results on the same scale measure we chose to convert all effects onto Cohen's D. The exception is effect sizes that were originally reported as Hedges' g or Cohen's q, which we in the analysis treat as equivalent to Cohen's D.

For the cases where a correlation coefficient is reported as the main effect measure, we convert the effect sizes to a Cohen's D measure using the following formula:

$$
D=\frac{2 r}{\sqrt{1-r^{2}}}
$$

And Fisher's $\mathrm{Z}$ is converted to $\mathrm{r}$ according to the inverse of the Fisher transformation, so that,

$$
r=\frac{\exp (2 Z)-1}{\exp (2 Z)+1}
$$

Which is again converted to D using formula [3]. These transformations follow from statistical theory and rely on an assumption that the data follow a bivariate normal distribution. ${ }^{79}$ For the cases where the main effect size is reported as the difference in percentage points between conditions, we divide the estimated treatment effect by the standard deviation of the dependent variable and obtain a Cohen's D measure of the effect size.

For the meta-analysis data, we extract the standard errors of the meta-analytic effect from the available published information. Most of the meta-analyses in our sample reported a $95 \%$ 
confidence interval along with the mean standardized meta-analytic effect. Using the fact that conventional meta-analysis techniques assume a normal distribution for the summary effect ${ }^{80}$ we could therefore derive the standard error of the summary effect by employing the definition of a confidence interval,

$$
\widehat{D} \pm 1.96 S E(\widehat{D})
$$

Where $\widehat{D}$ is the mean meta-analytic effect and 1.96 is the critical value of the standard normal distribution required to construct a $95 \%$ confidence interval. From formula 5 we derive the

standard error as $S E(\widehat{D})=\frac{(U-\widehat{D})}{1.96}$, where $\mathrm{U}$ is the reported upper limit of the confidence interval of the summary effect reported in the meta-analysis.

\section{Estimating the overall difference in meta-analytic and replication effect sizes}

To estimate the overall difference between the meta-analyses and replication estimates, we treat the difference between the summary effect produced by the meta-analysis and the summary effect produced by the replication as our main parameter of interest. Denote by $\mu_{M, l}$ the summary effect reported in the meta-analysis and denote by $\mu_{R, l}$ the summary effect reported in the multilab replication, where 1 indexes the literature to which these estimates belong. We denote the difference between these population parameters as $\Delta_{l} \equiv \mu_{M, l}-\mu_{R, l}$ and its expectation as $\Delta \equiv$ $E\left[\mu_{M, l}-\mu_{R, l}\right]$. The latter parameter - the mean difference between the meta-analyses and the replications - is what is being estimated in Figure 3 and the bottom of Figure 2.

Following conventional meta-analytic models ${ }^{81}$, we regard the parameters $\Delta_{l}$ as random draws from an overall random-effects distribution of effects with mean $\Delta$ and assumed common among-study variance $\tau_{\Delta}^{2}$. Under the assumption that each of the primary studies forming the basis for the overall mean are unbiased for the true effect in that subpopulation, the 
corresponding sample means $\tilde{\mu}_{M}$ and $\tilde{\mu}_{R}$ are unbiased estimators for the true means $E\left[\mu_{M, l,}\right]$ and $E\left[\mu_{R, l}\right]$ and the mean difference $\Delta$ may be estimated by a weighted average of the literaturespecific difference estimators $\widehat{\Delta}_{l}$. Our estimator for the true difference is given by the weighted average

$$
\widehat{\Delta}=\left[\frac{\sum_{l=1}^{L} \widehat{\omega}_{l} \widehat{\Delta}_{l}}{\sum_{l=1}^{L} \widehat{\omega}_{l}}\right]
$$

Here, $\widehat{\omega}_{l}$ are the weights attached to each study pair. If the summary effect in both the metaanalyses and replications are unbiased for the true effect, the expectation of measure [6] is given by

$$
E(\hat{\Delta})=\Delta=\frac{\sum_{l=1}^{L} \omega_{l} \Delta_{l}}{\sum_{l=1}^{L} \omega_{l}}=\frac{\sum_{l=1}^{L} \omega_{l} \mu_{M, l}}{\sum_{l=1}^{L} \omega_{l}}-\frac{\sum_{l=1}^{L} \omega_{l} \mu_{R, l}}{\sum_{l=1}^{L} \omega_{l}}=\mu_{M}-\mu_{R}
$$

If the meta-analysis is unbiased (as assumed when deriving the above measure) and each replication study is a random draw from a population distribution with the same mean as the meta-analysis distribution, then $E(\widehat{\Delta})=0$; There would be zero systematic difference between the results produced by the meta-analyses and the results produced by the replications when averaging over all literatures. A systematic difference - either positive or negative - would suggest either that the meta-analysis contains bias, that the replication studies contain bias, or that the mean effect produced by the replications and the mean effect produced by the metaanalyses would differ even in absence of bias.

There are two likely mechanisms that may cause our difference measure to systematically differ from zero. If there is publication bias or selective reporting in the primary studies or the meta-analysis, the meta-analysis is likely to overestimate the true mean effect across study populations. As the publication format of the multiple lab replications at least in 
theory rules out the potential for selective reporting or publication bias, this mechanism is unlikely to contribute to bias in our overall measure through bias in the replication effects. However, the mean replication effect may be underestimated if the studies subjected to replication are not random draws from the overall distribution of effects. That is, replicators may systematically select studies for replication that produce a lower effect than the true mean across study populations. The presence of this mechanism in our analysis sample would also produce a positive overall difference measure. In summary, it is theoretically likely that the difference measure is likely to be either zero or positive. Moreover, if the difference measure is systematically positive this could be attributed to either overestimation in the meta-analyses, replicator selection, or a combination of these factors.

We use three different meta-analytic models to estimate the systematic difference, each using a different choice of weight for each of the difference parameters. First, we use a randomeffects model - the conventional model choice - that a priori treats the true parameters as different draws from an overall distribution. Second, we report results from a fixed-effects model which a priori assumes that each parameter is identical so that $\Delta_{l}=\Delta \forall l$. The practical difference in estimation between these two approaches is that the fixed-effects model weights by the inverse of the estimated variance in each study pair so that $\widehat{\omega}_{l}=\frac{1}{v_{l}}$ where $v_{l}$ is the estimated "within-literature" variance of the parameter $\Delta_{l}$. The random effects model in addition provides a moment-based estimate of $\tau_{\Delta}^{2}$ and uses study weights $\widehat{\omega}_{l}=\frac{1}{v_{l}+\tau_{\Delta}^{2}}$, which means that the total variance of the random effects mean will be larger, so that the random effects model is more conservative. Finally, we also consider an unweighted average where each difference parameter is given equal weight in the estimation, and the standard error is just measured by $\frac{1}{L} \sqrt{\sum_{l=1}^{L} S E\left(\widehat{\Delta}_{l}\right)^{2}}$. 
While the random effects model is the typical model choice in meta-analysis, recent papers present arguments for the fixed-effects model in cases where the parameters under study may not be regarded as draws from a common distribution - even in model settings where there is heterogeneity in the underlying effect ${ }^{82}$. Also, some argue for using the fixed-effects model as it is more robust to publication bias than the random-effects model ${ }^{83}$. As it is not clear which model to prefer, we choose to report results for all our analyses using both models.

For inference in the fixed effects model, it is sufficient to invoke asymptotic normality in the total number of subjects and use a Z-test to test the null hypothesis that the assumed common effect across all study populations is zero. For the random effects model statistical inference is built on the assumption that the random effects are normally distributed ${ }^{80}$. For the unweighted measure, in addition to a parametric Z-test we conduct a nonparametric Wilcoxon signed-rank test that tests the null hypothesis that the difference parameters follow a symmetric distribution around zero against a two-sided alternative that the difference parameters do not follow a symmetric distribution around zero. Using the 17 pairs in our analysis sample we obtain a sum of negative ranks equal to 1 , which using a two-sided Wilcoxon signed-rank test yields a p-value below 0.001 . 
Supplementary Table 1. List of all studies that were assessed for eligibility for inclusion in our analysis sample.

\begin{tabular}{|c|c|c|c|c|}
\hline Original & Replication & Meta-analysis & Note on meta-analysis & Included \\
\hline Critcher \& Gilovich (2008) ${ }^{54}$ & Klein et al. (2018) ${ }^{13}$ & Henriksson $(2015)^{15}$ & Main estimate included & Yes \\
\hline Finkel et al. $(2002)^{55}$ & Cheung et al. $(2016)^{5}$ & Fehr et al. $(2010)^{16}$ & Sub-analysis (relationship commitment) from correction used. & Yes \\
\hline Galinsky et al. $(2006)^{56}$ & Ebersole $(2016)^{14}$ & Hall et al. $(2015)^{17}$ & Sub-analysis (recall) included in analysis & Yes \\
\hline Hauser et al. $(2007)^{57}$ & Klein et al. $(2018)^{13}$ & Feltz \& May $(2017)^{18}$ & Estimate from categorical data used & Yes \\
\hline Husnu \& Crisp (2010) ${ }^{58}$ & Klein et al. (2014) ${ }^{12}$ & Miles \& Crisp (2014) ${ }^{19}$ & Sub-analysis (intentions) included in analysis & Yes \\
\hline Jostmann, Lakens \& Schubert (2009) $)^{59}$ & Ebersole $(2016)^{14}$ & Rabelo et al. $(2015)^{20}$ & Main estimate included & Yes \\
\hline Mazar et al. $(2008)^{60}$ & $\begin{array}{l}\text { Verschuere et al. } \\
(2018)^{11}\end{array}$ & Belle \& Cantarelli $(2017)^{21}$ & Estimate from appendix included & Yes \\
\hline Monin \& Miller $(2001)^{61}$ & Ebersole $(2016)^{14}$ & Blanken et al. $(2015)^{22}$ & Main estimate included & Yes \\
\hline $\begin{array}{l}\text { Oppenheimer, Meyvis \& Davidenko } \\
(2009)^{52}\end{array}$ & Klein et al. $(2014)^{12}$ & Roth, Robbert \& Straus $(2014)^{23}$ & Sub-analysis (sunk costs) included in analysis & Yes \\
\hline Rand, Greene \& Nowak $(2012)^{62}$ & $(2017)^{7}$ & Rand $(2016)^{24}$ & ITT estimate included in analysis & Yes \\
\hline Schooler \& Engstler-Schooler $(1990)^{63}$ & Alogna et al. $(2014)^{2}$ & Meissner \& Brigham $(2001)^{25}$ & Main estimate included & Yes \\
\hline Schwarz, Strack \& Mai (1991) ${ }^{64}$ & Klein et al. $(2018)^{13}$ & Schimmack \& Oishi $(2005)^{26}$ & Random effects estimate included & Yes \\
\hline Sripada, Kessler \& Jonides $(2014)^{65}$ & Hagger et al. $(2016)^{4}$ & Hagger et al. $(2010)^{27}$ & Overall ego-depletion effect used & Yes \\
\hline Sripada, Kessler \& Jonides $(2014)^{65}$ & Hagger et al. $(2016)^{4}$ & Carter et al. $(2015)^{28}$ & $\begin{array}{l}\text { Included in robustness check in replacement of Hagger et al. (2010). Main } \\
\text { random effects estimate used }\end{array}$ & In robustness check \\
\hline Srull \& Wyer (1979) ${ }^{66}$ & McCarthy et al. $(2018)^{10}$ & DeCoster \& Claypool (2004) $)^{29}$ & Main estimate included, sub-analysis does not report all relevant info & Yes \\
\hline Strack, Martin \& Stepper $(1988)^{67}$ & $\begin{array}{l}\text { Wagenmakers et al. } \\
(2016)^{6}\end{array}$ & Coles et al. $(2017)^{30}$ & $\begin{array}{l}\text { Main estimate included, Wagenmakers et al. (2016) was a large part of } \\
\text { relevant sub-analysis }\end{array}$ & Yes \\
\hline Tversky \& Kahneman $(1981)^{53}$ & Klein et al. (2014) ${ }^{12}$ & Kühberger $(1998)^{31}$ & Sub-analysis (Asian disease) included in analysis & Yes \\
\hline Anderson et al. (2012) ${ }^{68}$ & Klein et al. (2018) ${ }^{13}$ & Pinquart \& Sörensen $(2000)^{32}$ & Excluded: No match & No \\
\hline Boroditsky $(2000)^{69}$ & Ebersole $(2016)^{14}$ & Stickles \& Lewis $(2018)^{33}$ & $\begin{array}{l}\text { Excluded: Meta-analysis does not look at the difference between treatment } \\
\text { and control, only average in control group }\end{array}$ & No \\
\hline Cacioppo, Petty \& Morris $(1983)^{70}$ & Ebersole (2016) ${ }^{14}$ & Von Stumm \& Ackerman $(2013)^{34}$ & Excluded: No match & No \\
\hline Cacioppo, Petty \& Morris $(1983)^{70}$ & Ebersole $(2016)^{14}$ & Stiff $(1986)^{35}$ & Excluded: No match & No \\
\hline Caruso, Vohs, Baxter \& Waytz (2013) $)^{71}$ & Klein et al. $(2014)^{12}$ & Vadillo, Hardwicke, \& Shanks $(2016)^{36}$ & Excluded: Not a proper meta-analysis & No \\
\hline Caruso, Vohs, Baxter \& Waytz (2013) $)^{71}$ & Klein et al. (2014) $)^{12}$ & Schuler \& Wänke $(2016)^{37}$ & Excluded: Not a proper meta-analysis & No \\
\hline Graham, Haidt \& Nosek (2009) ${ }^{72}$ & Klein et al. (2018) ${ }^{13}$ & Skitka, Morgan \& Wisneski $(2015)^{38}$ & Excluded: No match & No \\
\hline Graham, Haidt \& Nosek (2009) ${ }^{72}$ & Klein et al. $(2018)^{13}$ & $\begin{array}{l}\text { Kivikangas, Lönnqvist \& Ravaja } \\
(2019)^{39}\end{array}$ & Loyalty estimate included, others used in robustness checks & Yes \\
\hline Inbar et al. $(2009)^{73}$ & Klein et al. (2018) ${ }^{13}$ & Terrizzi, Shook \& McDaniel $(2013)^{40}$ & Excluded: No match & No \\
\hline Inbar et al. $(2009)^{73}$ & Klein et al. $(2018)^{13}$ & Kiss, Morrison \& Morrison (2018) $)^{41}$ & Excluded: No match, not same outcome variable & No \\
\hline Jacowitz \& Kahneman $(1995)^{74}$ & Klein et al. $(2014)^{12}$ & DeCoster \& Claypool (2014) $)^{29}$ & Excluded: No match & No \\
\hline Jacowitz \& Kahneman $(1995)^{74}$ & Klein et al. (2014) $)^{12}$ & Orr \& Guthrie (2006) ${ }^{42}$ & Excluded: No match & No \\
\hline Nosek, Banaji \& Greenwald (2002) 75 & Klein et al. (2014) ${ }^{12}$ & Greenwald et al. (2009) ${ }^{43}$ & Excluded: No match & No \\
\hline Nosek, Banaji \& Greenwald (2002) 75 & Klein et al. (2014) ${ }^{12}$ & Hofmann et al. $(2005)^{44}$ & Excluded: No match & No \\
\hline Nosek, Banaji \& Greenwald (2002) & Klein et al. $(2014)^{12}$ & Lindberg et al. $(2010)^{45}$ & Excluded: No match & No \\
\hline Nosek, Banaji \& Greenwald (2002) ${ }^{75}$ & Klein et al. $(2014)^{12}$ & Reilly, Neumann \& Andrews $(2015)^{46}$ & Excluded: No match & No \\
\hline Ross, Greene \& House $(1977)^{76}$ & Klein et al. $(2018)^{13}$ & Mullen $(1985)^{47}$ & Excluded: Data not available & No \\
\hline $\operatorname{Rugg}(1941)^{77}$ & Klein et al. (2014) ${ }^{12}$ & Holleman $(1999)^{48}$ & Excluded: Data not available & No \\
\hline Schooler \& Engstler-Schooler $(1990)^{63}$ & Alogna et al. $(2014)^{2}$ & Meissner, Sporer \& Susa $(2008)^{49}$ & Excluded: No match & No \\
\hline Schwarz, Strack \& Mai (1991) ${ }^{64}$ & Klein et al. $(2018)^{13}$ & $\begin{array}{l}\text { Heller, Watson \& Ilies }(2004)^{50} \\
\text { Blanken, van de Ven \& Zeelenberg }\end{array}$ & Excluded: No match & No \\
\hline Zhong \& Liljenquist (2006) ${ }^{78}$ & $\begin{array}{l}\text { Klein et al. }(2018)^{13} \\
\text { Wagenmakers et al. }\end{array}$ & $(2015)^{22}$ & Excluded: No match & No \\
\hline Strack, Martin \& Stepper $(1988)^{67}$ & $(2016)^{6}$ & Matsumoto $(1987)^{51}$ & Excluded: No match, not same outcome variable & No \\
\hline
\end{tabular}


Supplementary Table 2. Results from a random-effects meta-regression of the difference measure on a constant term and a dummy for whether the replication successfully detected an effect in the direction of the original study.

\section{(1)}

\begin{tabular}{lc}
\hline Successful replication $(\mathrm{p}=0.05)$ & -0.141 \\
& $(0.0807)$ \\
{$[0.1003]$}
\end{tabular}

Successful replication $(\mathrm{p}=0.005)$

$-0.157$

$(0.0795)$

[0.0662]

Studies that failed to replicate

$$
0.345
$$

0.342

$(0.0571)$

$(0.0521)$

[0.0000] $[0.0000]$

\begin{tabular}{ll}
$N$ & 17 \\
\hline
\end{tabular}
17

Standard errors in parentheses

$p$-values in brackets

Note: The first column defines "replication success" as the replication detecting an effect at $p=0.05$ in the same direction as the original study and the second column defines "replication success" as the replication detecting an effect at $p=0.005$ in the direction of the original study 
Supplementary Table 3. Results from meta-analyses comparing the original effect sizes and the meta-analytic effect sizes. $N=14$.

\begin{tabular}{ccccc}
\hline Method & Difference & 95\% CI LL & 95\% CI UL & P-value \\
\hline Unweighted & 0.166 & 0.045 & 0.287 & 0.007 \\
Fixed effects & 0.089 & 0.010 & 0.169 & 0.027 \\
Random effects & 0.134 & 0.008 & 0.260 & 0.037 \\
\hline
\end{tabular}




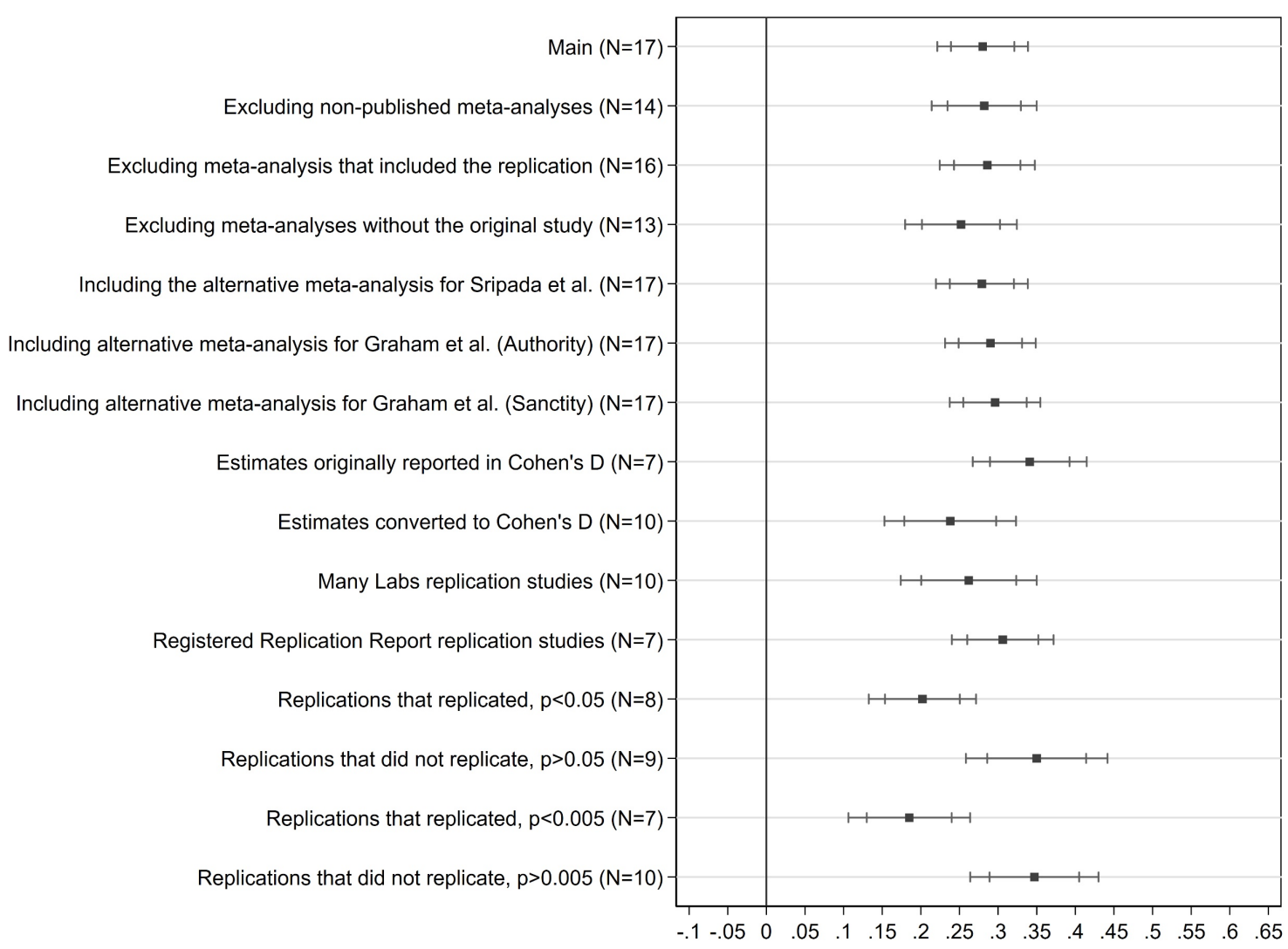

Supplementary Figure 1. Robustness test and sub-group analyses of the difference in the mean meta-analytic effect size and the mean replication effect size for all the studied effects. Results for the unweighted mean. For each robustness test and sub-group analysis we plot the $95 \%$ and $99.5 \%$ confidence interval of the difference in the mean meta-analytic effect size and the mean replication effect size for all the studied effects. "Main" is our main estimate from panel A of Fig. 2. 


\section{Supplementary references}

1. Simons, D. J., Holcombe, A. O., \& Spellman, B. A. (2014). An introduction to registered replication reports at perspectives on psychological science. Perspectives on Psychological Science, 9(5), 552-555.

2. Alogna, V. K., Attaya, M. K., Aucoin, P., Bahník, Š., Birch, S., Birt, A. R., ... \& Buswell, K. (2014). Registered replication report: Schooler and engstler-schooler (1990). Perspectives on Psychological Science, 9(5), 556-578.

3. Eerland, A., Sherrill, A. M., Magliano, J. P., Zwaan, R. A., Arnal, J. D., Aucoin, P., ... \& Crocker, C. (2016). Registered replication report: Hart \& Albarracín (2011). Perspectives on Psychological Science, 11(1), 158-171.

4. Hagger, M. S., Chatzisarantis, N. L., Alberts, H., Anggono, C. O., Batailler, C., Birt, A. R., ... \& Calvillo, D. P. (2016). A multilab preregistered replication of the ego-depletion effect. Perspectives on Psychological Science, 11(4), 546-573.

5. Cheung, I., Campbell, L., LeBel, E. P., Ackerman, R. A., Aykutoğlu, B., Bahník, Š., ... \& Carcedo, R. J. (2016). Registered Replication Report: Study 1 from Finkel, Rusbult, Kumashiro, \& Hannon (2002). Perspectives on Psychological Science, 11(5), 750-764.

6. Wagenmakers, E. J., Beek, T., Dijkhoff, L., Gronau, Q. F., Acosta, A., Adams Jr, R. B., ... \& Bulnes, L. C. (2016). Registered Replication Report: Strack, Martin, \& Stepper (1988). Perspectives on Psychological Science, 11(6), 917-928.

7. Bouwmeester, S., Verkoeijen, P. P., Aczel, B., Barbosa, F., Bègue, L., Brañas-Garza, P., ... \& Evans, A. M. (2017). Registered replication report: Rand, greene, and nowak (2012). Perspectives on Psychological Science, 12(3), 527-542.

8. Bouwmeester, S., Verkoeijen, P. P., Aczel, B., Barbosa, F., Bègue, L., Brañas-Garza, P., ... \& Evans, A. M. (2017). Registered replication report: Rand, greene, and nowak (2012). Perspectives on Psychological Science, 12(3), 527-542.

9. O’Donnell, M., Nelson, L. D., Ackermann, E., Aczel, B., Akhtar, A., Aldrovandi, S., ... \& Balatekin, N. (2018). Registered Replication Report: Dijksterhuis and van Knippenberg (1998). Perspectives on Psychological Science, 13(2), 268-294.

10. McCarthy, R. J., Skowronski, J. J., Verschuere, B., Meijer, E. H., Jim, A., Hoogesteyn, K., ... \& Barbosa, F. (2018). Registered replication report on Srull and Wyer (1979). Advances in Methods and Practices in Psychological Science, 1(3), 321-336. 
11. Verschuere, B., Meijer, E. H., Jim, A., Hoogesteyn, K., Orthey, R., McCarthy, R. J., ... \& Barbosa, F. (2018). Registered replication report on Mazar, Amir, and Ariely (2008). Advances in Methods and Practices in Psychological Science, 1(3), 299-317.

12. Klein, R. A. et al. Investigating variation in replicability: a "many labs" replication project. Social Psychology 45, 142-152 (2014).

13. Klein, R. A., Vianello, M., Hasselman, F., Adams, B. G., Adams Jr, R. B., Alper, S., ... \& Batra, R. (2018). Many Labs 2: Investigating variation in replicability across samples and settings. Advances in Methods and Practices in Psychological Science, 1(4), 443490.

14. Ebersole, C. R., Atherton, O. E., Belanger, A. L., Skulborstad, H. M., Allen, J. M., Banks, J. B., ... \& Brown, E. R. (2016). Many Labs 3: Evaluating participant pool quality across the academic semester via replication. Journal of Experimental Social Psychology, 67, 68-82.

15. Henriksson, K. A. C. (2015). Irrelevant quantity effects: a meta-analysis (Doctoral dissertation). Retrieved from: http://csufresnodspace.calstate.edu/bitstream/handle/10211.3/161647/HENRIKSSON Kerstin.pdf?se quence $=1$

16. Fehr, R., Gelfand, M. J., \& Nag, M. (2010). The road to forgiveness: a meta-analytic synthesis of its situational and dispositional correlates. Psychological bulletin, 136(5), 894.

17. Hall, J. A., Mast, M. S., \& Latu, I. M. (2015). The vertical dimension of social relations and accurate interpersonal perception: A meta-analysis. Journal of Nonverbal Behavior, $39(2), 131-163$.

18. Feltz, A., \& May, J. (2017). The means/side-effect distinction in moral cognition: A meta-analysis. Cognition, 166, 314-327.

19. Miles, E., \& Crisp, R. J. (2014). A meta-analytic test of the imagined contact hypothesis. Group Processes \& Intergroup Relations, 17(1), 3-26.

20. Rabelo, A. L., Keller, V. N., Pilati, R., \& Wicherts, J. M. (2015). No effect of weight on judgments of importance in the moral domain and evidence of publication bias from a meta-analysis. PloS one, 10(8), e0134808.

21. Belle, N., \& Cantarelli, P. (2017). What Causes Unethical Behavior? A Meta-Analysis to Set an Agenda for Public Administration Research. Public Administration Review, 77(3), 327-339. 
22. Blanken, I., van de Ven, N., \& Zeelenberg, M. (2015). A meta-analytic review of moral licensing. Personality and Social Psychology Bulletin, 41(4), 540-558.

23. Roth, S., Robbert, T., \& Straus, L. (2015). On the sunk-cost effect in economic decisionmaking: a meta-analytic review. Business research, 8(1), 99-138.

24. Rand, D. G. (2016). Cooperation, fast and slow: Meta-analytic evidence for a theory of social heuristics and self-interested deliberation. Psychological Science, 27(9), 11921206.

25. Meissner, C. A., \& Brigham, J. C. (2001). A meta-analysis of the verbal overshadowing effect in face identification. Applied Cognitive Psychology: The Official Journal of the Society for Applied Research in Memory and Cognition, 15(6), 603-616.

26. Schimmack, U., \& Oishi, S. (2005). The influence of chronically and temporarily accessible information on life satisfaction judgments. Journal of personality and social psychology, 89(3), 395.

27. Hagger, M. S., Wood, C., Stiff, C., \& Chatzisarantis, N. L. (2010). Ego depletion and the strength model of self-control: a meta-analysis. Psychological bulletin, 136(4), 495.

28. Carter, E. C., Kofler, L. M., Forster, D. E., \& McCullough, M. E. (2015). A series of meta-analytic tests of the depletion effect: self-control does not seem to rely on a limited resource. Journal of Experimental Psychology: General, 144(4), 796.

29. DeCoster, J., \& Claypool, H. M. (2004). A meta-analysis of priming effects on impression formation supporting a general model of informational biases. Personality and Social Psychology Review, 8(1), 2-27.

30. Coles, N., Larsen, J., \& Lench, H. (2017). A meta-analysis of the facial feedback hypothesis literature. Retrieved from: https://psyarxiv.com/svjru

31. Kühberger, A. (1998). The influence of framing on risky decisions: A meta-analysis. Organizational Behavior and Human Decision Processes, 75(1), 23-55.

32. Pinquart, M., \& Sörensen, S. (2000). Influences of socioeconomic status, social network, and competence on subjective well-being in later life: a meta-analysis. Psychology and Aging, 15(2), 187.

33. Stickles, E., \& Lewis, T. N. (2018). Wednesday's Meeting Really Is on Friday: A MetaAnalysis and Evaluation of Ambiguous Spatiotemporal Language. Cognitive Science, 42(3), 1015-1025.

34. Von Stumm, S., \& Ackerman, P. L. (2013). Investment and intellect: A review and meta-analysis. Psychological Bulletin, 139(4), 841. 
35. Stiff, J. B. (1986). Cognitive processing of persuasive message cues: A meta-analytic review of the effects of supporting information on attitudes. Communications Monographs, 53(1), 75-89.

36. Vadillo, M. A., Hardwicke, T. E., \& Shanks, D. R. (2016). Selection bias, vote counting, and money-priming effects: A comment on Rohrer, Pashler, and Harris (2015) and Vohs (2015). Journal of Experimental Psychology: General, 145(5), 655-663.

37. Schuler, J., \& Wänke, M. (2016). A fresh look on money priming: Feeling privileged or not makes a difference. Social Psychological and Personality Science, 7(4), 366-373.

38. Skitka, L. J., Morgan, G. S., \& Wisneski, D. C. (2015). Political orientation and moral conviction: A conservative advantage or an equal opportunity motivator of political engagement? In J. Forgas, W. Crano, \& K. Fiedler (Eds.) Social psychology and politics. New York: Psychology Press.

39. Kivikangas, J., Järvelä, S., Fernández-Castilla, B., Lönnqvist, J., \& Ravaja, N. (2019, February 15). Meta-analysis of the relationship between moral foundations and political orientation. Retrieved from: https://doi.org/10.31219/osf.io/mbfwe

40. Terrizzi Jr, J. A., Shook, N. J., \& McDaniel, M. A. (2013). The behavioral immune system and social conservatism: A meta-analysis. Evolution and Human Behavior, 34(2), 99-108.

41. Kiss, M. J., Morrison, M. A., \& Morrison, T. G. (2018). A Meta-Analytic Review of the Association Between Disgust and Prejudice Toward Gay Men. Journal of Homosexuality, 1-23.

42. Orr, D., \& Guthrie, C. (2005). Anchoring, information, expertise, and negotiation: New insights from meta-analysis. Ohio St. J. on Disp. Resol., 21, 597.

43. Greenwald, A. G., Poehlman, T. A., Uhlmann, E. L., \& Banaji, M. R. (2009). Understanding and using the Implicit Association Test: III. Meta-analysis of predictive validity. Journal of Personality and Social Psychology, 97(1), 17.

44. Hofmann, W., Gawronski, B., Gschwendner, T., Le, H., \& Schmitt, M. (2005). A metaanalysis on the correlation between the Implicit Association Test and explicit self-report measures. Personality and Social Psychology Bulletin, 31(10), 1369-1385.

45. Lindberg, S. M., Hyde, J. S., Petersen, J. L., \& Linn, M. C. (2010). New trends in gender and mathematics performance: a meta-analysis. Psychological Bulletin, 136(6), 1123.

46. Reilly, D., Neumann, D. L., \& Andrews, G. (2015). Sex differences in mathematics and science achievement: A meta-analysis of National Assessment of Educational Progress assessments. Journal of Educational Psychology, 107(3), 645. 
47. Mullen, B. (1985). Strength and immediacy of sources: A meta-analytic evaluation of the forgotten elements of social impact theory. Journal of Personality and Social Psychology, 48(6), 1458.

48. Holleman, B. (1999). Wording effects in survey research using meta-analysis to explain the forbid/allow asymmetry. Journal of Quantitative Linguistics, 6(1), 29-40.

49. Meissner, C. A., Sporer, S. L., \& Susa, K. J. (2008). A theoretical review and metaanalysis of the description-identification relationship in memory for faces. European Journal of Cognitive Psychology, 20(3), 414-455.

50. Heller, D., Watson, D., \& Ilies, R. (2004). The role of person versus situation in life satisfaction: A critical examination. Psychological Bulletin, 130(4), 574.

51. Matsumoto, D. (1987). The role of facial response in the experience of emotion: More methodological problems and a meta-analysis. Journal of Personality and Social Psychology, 52(4), 769.

52. Oppenheimer, D. M., Meyvis, T., \& Davidenko, N. (2009). Instructional manipulation checks: Detecting satisficing to increase statistical power. Journal of Experimental Social Psychology, 45(4), 867-872.

53. Tversky, A., \& Kahneman, D. (1981). The framing of decisions and the psychology of choice. Science, 211(4481), 453-458.

54. Critcher, C. R., \& Gilovich, T. (2008). Incidental environmental anchors. Journal of Behavioral Decision Making, 21(3), 241-251.

55. Finkel, E. J., Rusbult, C. E., Kumashiro, M., \& Hannon, P. A. (2002). Dealing with betrayal in close relationships: Does commitment promote forgiveness?. Journal of Personality and Social Psychology, 82(6), 956.

56. Galinsky, A. D., Magee, J. C., Inesi, M. E., \& Gruenfeld, D. H. (2006). Power and perspectives not taken. Psychological Science, 17(12), 1068-1074.

57. Hauser, M., Cushman, F., Young, L., Kang-Xing Jin, R., \& Mikhail, J. (2007). A dissociation between moral judgments and justifications. Mind \& Language, 22(1), 121.

58. Husnu, S., \& Crisp, R. J. (2010). Elaboration enhances the imagined contact effect. Journal of Experimental Social Psychology, 46(6), 943-950.

59. Jostmann, N. B., Lakens, D., \& Schubert, T. W. (2009). Weight as an embodiment of importance. Psychological Science, 20(9), 1169-1174.

60. Mazar, N., Amir, O., \& Ariely, D. (2008). The dishonesty of honest people: A theory of self-concept maintenance. Journal of Marketing Research, 45(6), 633-644. 
61. Monin, B., \& Miller, D. T. (2001). Moral credentials and the expression of prejudice. Journal of Personality and Social Psychology, 81(1), 33.

62. Rand, D. G., Greene, J. D., \& Nowak, M. A. (2012). Spontaneous giving and calculated greed. Nature, 489(7416), 427.

63. Schooler, J. W., \& Engstler-Schooler, T. Y. (1990). Verbal overshadowing of visual memories: Some things are better left unsaid. Cognitive Psychology, 22(1), 36-71.

64. Schwarz, N., Strack, F., \& Mai, H. P. (1991). Assimilation and contrast effects in partwhole question sequences: A conversational logic analysis. Public Opinion Quarterly, 55(1), 3-23.

65. Sripada, C., Kessler, D., \& Jonides, J. (2014). Methylphenidate blocks effort-induced depletion of regulatory control in healthy volunteers. Psychological Science, 25(6), 1227-1234.

66. Srull, T. K., \& Wyer, R. S. (1979). The role of category accessibility in the interpretation of information about persons: Some determinants and implications. Journal of Personality and Social Psychology, 37(10), 1660.

67. Strack, F., Martin, L. L., \& Stepper, S. (1988). Inhibiting and facilitating conditions of the human smile: a nonobtrusive test of the facial feedback hypothesis. Journal of Personality and Social Psychology, 54(5), 768.

68. Anderson, C., Kraus, M. W., Galinsky, A. D., \& Keltner, D. (2012). The local-ladder effect: Social status and subjective well-being. Psychological Science, 23(7), 764-771.

69. Boroditsky, L. (2000). Metaphoric structuring: Understanding time through spatial metaphors. Cognition, 75(1), 1-28.

70. Cacioppo, J. T., Petty, R. E., \& Morris, K. J. (1983). Effects of need for cognition on message evaluation, recall, and persuasion. Journal of Personality and Social Psychology, 45(4), 805.

71. Caruso, E. M., Vohs, K. D., Baxter, B., \& Waytz, A. (2013). Mere exposure to money increases endorsement of free-market systems and social inequality. Journal of Experimental Psychology: General, 142(2), 301.

72. Graham, J., Haidt, J., \& Nosek, B. A. (2009). Liberals and conservatives rely on different sets of moral foundations. Journal of Personality and Social Psychology, 96(5), 1029.

73. Inbar, Y., Pizarro, D. A., Knobe, J., \& Bloom, P. (2009). Disgust sensitivity predicts intuitive disapproval of gays. Emotion, 9(3), 435. 
74. Jacowitz, K. E., \& Kahneman, D. (1995). Measures of anchoring in estimation tasks. Personality and Social Psychology Bulletin, 21(11), 1161-1166.

75. Nosek, B. A., Banaji, M. R., \& Greenwald, A. G. (2002). Math= male, me= female, therefore math $\neq$ me. Journal of Personality and Social Psychology, 83(1), 44.

76. Ross, L., Greene, D., \& House, P. (1977). The "false consensus effect": An egocentric bias in social perception and attribution processes. Journal of Experimental Social Psychology, 13(3), 279-301.

77. Rugg, D. (1941). Experiments in wording questions: II. Public Opinion Quarterly, 5(1), 91.

78. Zhong, C. B., \& Liljenquist, K. (2006). Washing away your sins: Threatened morality and physical cleansing. Science, 313(5792), 1451-1452.

79. Borenstein, M., Hedges, L. V., Higgins, J. P., \& Rothstein, H. R. (2011). Introduction to meta-analysis. John Wiley \& Sons.

80. Higgins, J. P., Thompson, S. G., \& Spiegelhalter, D. J. (2009). A re-evaluation of random-effects meta-analysis. Journal of the Royal Statistical Society: Series A (Statistics in Society), 172(1), 137-159.

81. Whitehead, A., \& Whitehead, J. (1991). A general parametric approach to the metaanalysis of randomized clinical trials. Statistics in Medicine, 10(11), 1665-1677.

82. Rice, K., Higgins, J., \& Lumley, T. (2018). A re-evaluation of fixed effect (s) metaanalysis. Journal of the Royal Statistical Society: Series A (Statistics in Society), 181(1), 205-227.

83. Ioannidis, John, P.A., Stanley, T.D., \& Doucouliagos, H. (2017). The Power of Bias in Economics Research, The Economic Journal, 127(605), 236-F26

84. Thaler, R. (1985). Mental accounting and consumer choice. Marketing Science, 4(3), 199-214.

85. Baumeister, R. F., Bratslavsky, E., Muraven, M., \& Tice, D. M. (1998). Ego depletion: Is the active self a limited resource? Journal of Personality and Social Psychology, 74, $1252-1265$. 